\title{
Dynamic Mechanical Behavior of Dry and Water Saturated Igneous Rock with Acoustic Emission Monitoring
}

\author{
Jun Guo, ${ }^{1,2}$ Guo-rui Feng ${ }^{D},{ }^{1,2}$ Ting-ye Qi, ${ }^{1,2}$ Pengfei Wang, ${ }^{1,2}$ Jian Yang, ${ }^{3}$ Zhen Li, $^{1,2}$ \\ Jinwen Bai, ${ }^{1,2}$ Xianjie Du, ${ }^{1,2}$ and Zehua Wang ${ }^{1,2}$ \\ ${ }^{1}$ College of Mining Engineering, Taiyuan University of Technology, Shanxi 030024, China \\ ${ }^{2}$ Shanxi Province Research Center of Green Mining Engineering Technology, Shanxi 030024, China \\ ${ }^{3}$ Department of Mining Engineering West Virginia University, Morgantown, WV 26506-6070, USA \\ Correspondence should be addressed to Guo-rui Feng; fguorui@163.com
}

Received 12 September 2017; Revised 24 January 2018; Accepted 26 February 2018; Published 17 April 2018

Academic Editor: Xinglin Lei

Copyright (C) 2018 Jun Guo et al. This is an open access article distributed under the Creative Commons Attribution License, which permits unrestricted use, distribution, and reproduction in any medium, provided the original work is properly cited.

\begin{abstract}
The uniaxial cyclic loading tests have been conducted to study the mechanical behavior of dry and water saturated igneous rock with acoustic emission (AE) monitoring. The igneous rock samples are dried, naturally immersed, and boiled to get specimens with different water contents for the testing. The mineral compositions and the microstructures of the dry and water saturated igneous rock are also presented. The dry specimens present higher strength, fewer strains, and rapid increase of AE count subjected to the cyclic loading, which reflects the hard and brittle behavior and strong burst proneness of igneous rock. The water saturated specimens have lower peak strength, more accumulated strains, and increase of AE count during the cyclic loading. The damage of the igneous rocks with different water contents has been identified by the Felicity Ratio Analysis. The cyclic loading and unloading increase the dislocation between the mineral aggregates and the water-rock interactions further break the adhesion of the clay minerals, which jointly promote the inner damage of the igneous rock. The results suggest that the groundwater can reduce the burst proneness of the igneous rock but increase the potential support failure of the surrounding rock in igneous invading area. In addition, the results inspire the fact that the water injection method is feasible for softening the igneous rock and for preventing the dynamic disasters within the roadways and working faces located in the igneous intrusion area.
\end{abstract}

\section{Introduction}

Igneous intrusions that penetrate rock and coal strata are a common geologic phenomenon [1-3]. In China, the whole Permo-Carboniferous coal system was invaded by magma from the south area to the north area. The cooling magma can form hard igneous sill and dyke [4]. With the increasing mining depth of coal mines, intrusive igneous rock is usually found around roadways and in the overlying strata above mining stopes [5]. Influenced by the multiple human mining activities and the natural shock and vibrations of earthquake, the hard igneous rock would suddenly break, instantly releasing a tremendous amount of elastic strain energy, which will easily induce the occurrence of complex dynamic disasters, such as rock bursts, water inrush, and gas outbursts [610]. The dynamic disasters in coal mines caused by the intrusive igneous rock impact the safety and productivity of the coal mines. Therefore, it is significant to investigate the deformation and failure characteristics of igneous rock and further study burst risk assessment, monitoring, and forecasting as well as burst control measures.

Cyclic loading and unloading tests with acoustic emission monitoring are an effective approach to quantitatively measuring deformation and damage characteristics of various materials [11-20]. Sherif et al. [12] captured and analyzed AE signals to characterize the crack formation and crack width development in the cyclic loading processes. AE method had been utilized to capture the fatigue crack growth of concrete mortar under cyclic contact loading [14]. Chilali et al. [15] studied the effect of water ageing on the mechanical behavior of flax fibre-reinforced thermoplastic and thermosetting composites using load-unload cyclic tests with $\mathrm{AE}$ monitoring. The features of $\mathrm{AE}$ signals were found to be very useful in classifying damage mechanisms of the 
material. In addition to the fibre-reinforced composites and metallic materials, the AE method also is applied to research the mechanical behaviors of rock material. Browning et al. [16] used cumulative $\mathrm{AE}$ hits and $\mathrm{AE}$ hits rate to evaluate the onset and evolution of new crack damage caused by inelastic processes in rocks under different loading conditions. Trippetta et al. [17] found that there is a certain relation between the AE energy and the elastic moduli of seismogenic Triassic Evaporites subjected to cyclic stressing. Wang and Park [18] carried out cyclic loading tests on granite samples and pointed out that the strain energy analysis is necessary for the prediction of rock burst hazard before a practical mining activity. Fan et al. [19] concluded that the intervals of discontinuous cyclic loading strongly change the mechanical response of the salt samples. The fatigue life and the residual strain prior to the failure of the salt samples can be verified by the acoustic emission (AE) activity. Yue [20] proposed a tentative formula for predicting the level of damage and the closeness to failure of a RC column on the bases of $\mathrm{AE}$ monitoring technique. They proved that that $\mathrm{AE}$ technique is very effective for assessing the damage of RC columns subjected to earth quake-type loadings. He et al. [21] conducted a true-triaxial unloading test on limestone with acoustic emission monitoring and researched the relationship between the characteristics of rock burst and AE parameters. Tan et al. [22] found that the AE characteristics can be used to predict the rock burst tendency of the coal-rock combination body. The Kaiser Effect [23] and Felicity Effect [24] of rock were found and used to reflect the damage and failure characteristics of rock materials $[25,26]$. Not just in laboratory tests, the acoustic emission and microseismic monitoring are also applied to detect faults/breaking signals for both healthy evaluation and disaster control in mining engineering [27-29].

In addition to the various loading actions, groundwater has significant effect on the mechanical properties of rock materials [30]. Coupling of water-rock interaction is very complex, which has aroused extensive attention among researchers. The water content is known as one of the most notable factors for lowering the strength of rocks [31]. A large number of studies [32-34] consistently show that the water-rock interaction undermines the mechanical property of rock, which is mainly found expressed in strength decrease, the change of the deformation, and failure characteristics. $\mathrm{Li}$ et al. [35] suggested that moisture content has a significant effect on shear properties reduction of both sandstone and mudstone, which must be considered in mining or excavation processes. Lei et al. [36] indicated that the drainage conditions have clear effect on the mode of deformation of porous rocks and the diffusion of pore pressure, which leads to a significant reduction in rock strength and stabilization of the dynamic rupture process. Some researchers have revealed that a small increase in water content may significantly lower the strength and stiffness of rock $[30,37,38]$. Actually, the surrounding igneous rock is commonly found immersed in groundwater during the extraction of coal seams in PermoCarboniferous coal system. Thus, it is necessary to study the influence of water-rock interaction on the mechanical properties of igneous rock.
This paper presents the microstructures and mineral compositions of the igneous rock firstly and then shows the results of uniaxial compressive tests with incremental cyclic loading and acoustic emission (AE) monitoring of the dry and different water saturated igneous rock specimens. The stress-strain curves of the specimens are compared with each other. The evolution of the accumulated AE count is shown to be strongly dependent on the cycle number and water saturation level, which is explained by the evolution of the damage accumulation caused by coupled effect of water-rock interaction and the incremental cyclic loading in the igneous rock. Besides that, Felicity Ratio is discussed to reveal the plastic deformation and stability of the igneous specimens with different water content.

\section{Experimental Conditions and Methodology}

The igneous rock samples were collected from the Tashan coal mine in China. The designed annual production capacity of the mine is 15 million tons, which is one of the largest coal mines in China. The coal seam being extracted in the mine is the no. 3-5 coal seam, which is buried in PermoCarboniferous coal system. The thickness of the no. 3-5 coal seam is as large as $20 \mathrm{~m}$ and the layered igneous sill is $30.5 \mathrm{~km}^{2}$ overlaying the coal seam.

Firstly, the igneous rock was processed into rock slices to identify its lithology. The X-ray diffraction and transmission and scanning electron microscopic methods were used to investigate the mineral components and microstructures of the igneous rock. The instruments are shown in Figure 1.

Then, the samples were processed into cylinders with $50 \mathrm{~mm}$ in diameter and $100 \mathrm{~mm}$ in length (Figure 2(a)). The specimens were divided into three groups and each group has three specimens. Under the guidance of the Code for Rock Tests of Hydroelectric and Water Conservancy Engineering (SL 264-2001) of China, the preliminary tests are conducted and indicate that the water content of the dry igneous rock specimens does not increase more than 8 days and 24 hours under natural temperature water and boiling water, respectively. According to the above-mentioned procedures the specimens with different water content (dry, natural water saturated, and boiled water saturated) were obtained:

(1) Drying: the specimens (1\#, 2\#, and 3\#) were dried 24 hours in an electric dry oven and the temperature was set to $105^{\circ} \mathrm{C}$ (Figure 2(b)).

(2) Natural temperature immersed saturated: the specimens ( $4 \#, 5 \#$, and $6 \#)$ were immersed 8 days in natural temperature water (Figure 2(c)).

(3) Boiled saturated: the specimens (7\#,8\#, and 9\#) were immersed 24 hours in boiling water and the temperature is $100^{\circ} \mathrm{C}$ (Figure 2(d)).

In this study, during the uniaxial compression strength (UCS) test, the specimens were subjected to an incremental cyclic axial loading until failure using a conventional mechanical rigid testing machine. The initial and lower limits of the load applied on the specimens are $P_{0}=40 \mathrm{kN}$ and $P_{\min }=10 \mathrm{kN}$, respectively. The incremental load is set to 


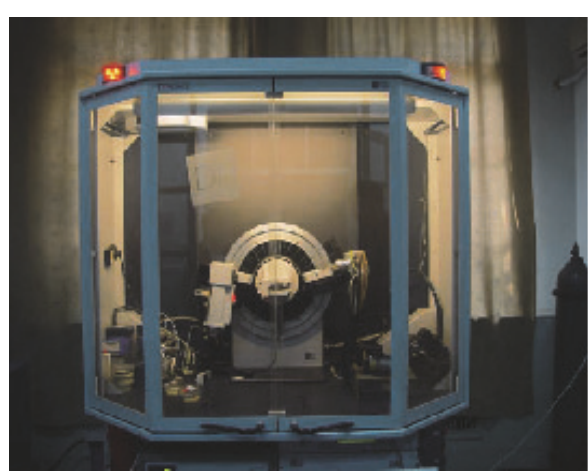

(a)

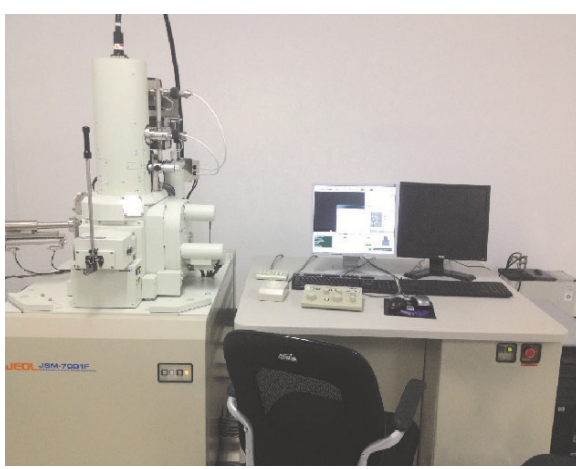

(b)

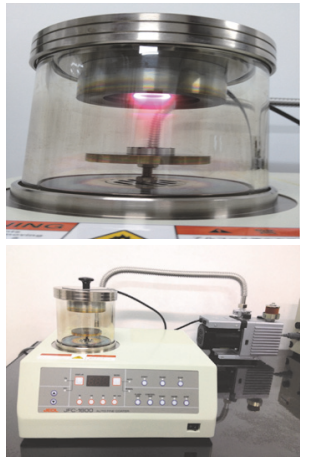

FIGURE 1: D8 Advance X-ray diffractometer (a) and JSM-7001F Field Emission Transmission Electron Microscopy (b).

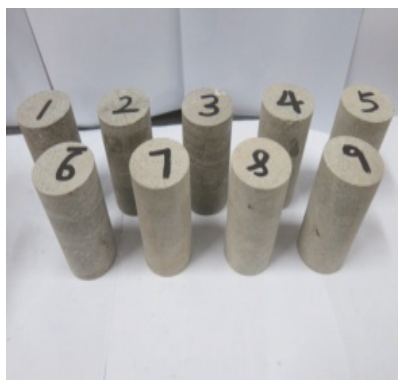

(a)

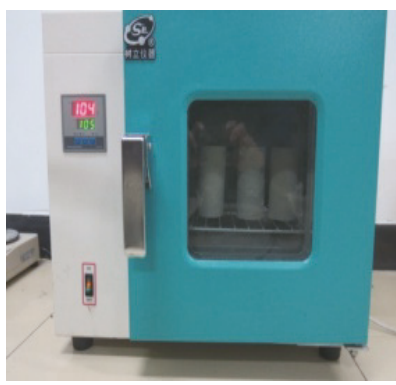

(b)

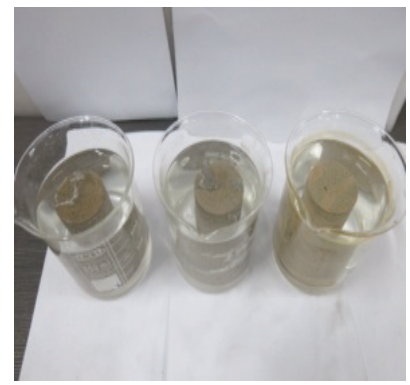

(c)

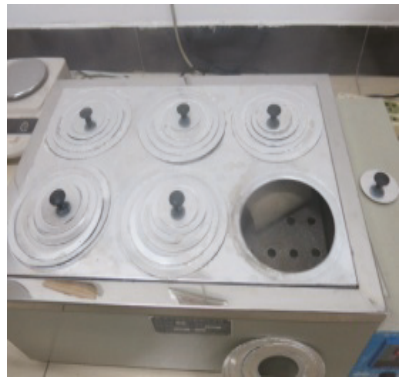

(d)

Figure 2: Natural specimens (a), dry specimens (b), natural immersed saturated specimens (c), and boiled saturated specimens (d).

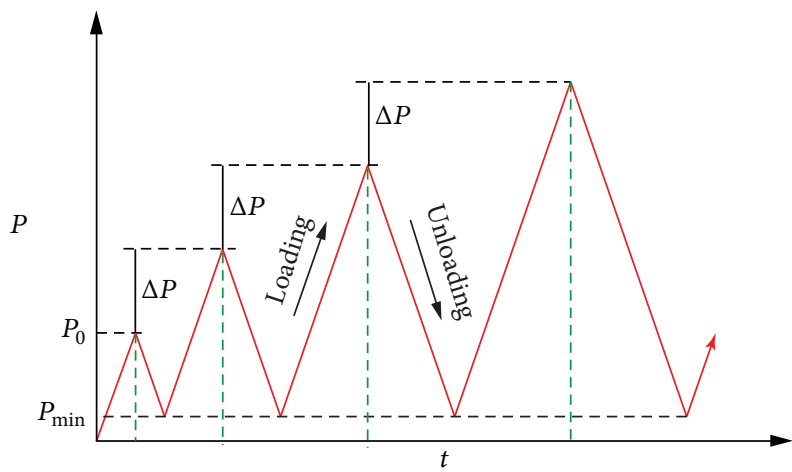

Figure 3: Loading path. The initial load $P_{0}=40 \mathrm{kN}$, the lower limit $P_{\min }=10 \mathrm{kN}$, and the incremental load $\Delta P=40 \mathrm{kN}$.

$\Delta P=40 \mathrm{kN}$. The loading-unloading velocities were both $0.002 \mathrm{~mm} / \mathrm{s}$. The loading path shown in Figure 3 was applied on each group of the specimens. Three duplicate tests for each group specimens were conducted to enhance the reliability of the results.

To characterize the damage and its evolution of the igneous rock, Micro-II digital AE system (Physical Acoustics, NJ, USA) was employed to monitor the AEs in the specimens under the cyclic compression. The two pairs of piezoelectric receivers were fixed on the sample surface at $1 / 4$ and $3 / 4$ to orientate the AEs. The AE sampling frequency and threshold were set to $1 \mathrm{MHz}$ and $40 \mathrm{~dB}$, respectively. The test system is shown in Figure 4.

\section{Results and Discussion}

The rock thin section, mineral components, and microstructures of the igneous rock are shown in Figures 5 and 6 . Water contents of the natural water saturated and boiled water saturated specimens are calculated. Then, the stressstrain curves, residual strains, and accumulated residual strains of specimens with different water contents under the incremental cyclic loading are described. Additionally, the stress and AE count of specimens with different water contents during the cyclic loading are compared. Lastly, the Felicity Ratios of the igneous rock in different water saturation states are analyzed. Those results are shown in the following sections, respectively.

3.1. Lithology and Mineral Components. The igneous rock was identified as lamprophyre based on the rock thin section (Figure $5(\mathrm{a})$ ), which is mainly composed of dioritic porphyrite and some clay minerals. Some microvoids can be found on the surface of the rock samples and the magnified image (Figure 5(b)) shows that the microvoids extend to the interior of the rock and these microvoids provide the pathways for water. Figure 5(c) suggests that the lamprophyre mainly contains the orthoclase, dolomite, pyroxmangite, bloedite, quartzite, and some clay minerals. The content of the orthoclase reaches 


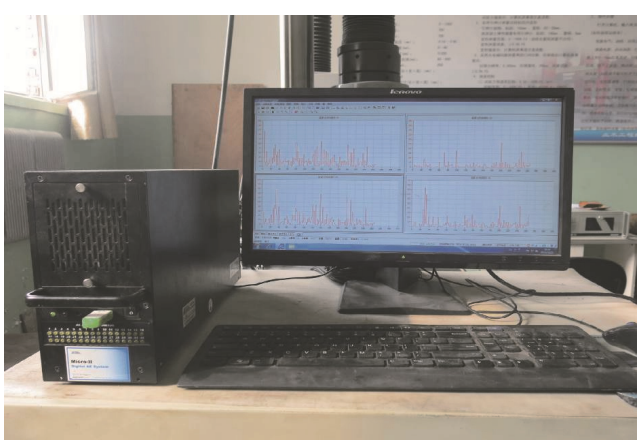

(a)

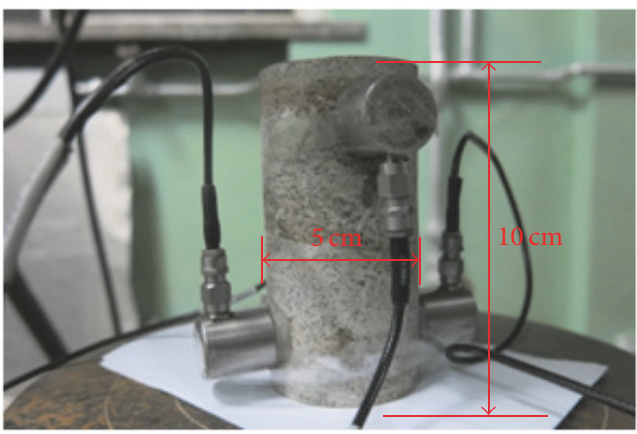

(b)

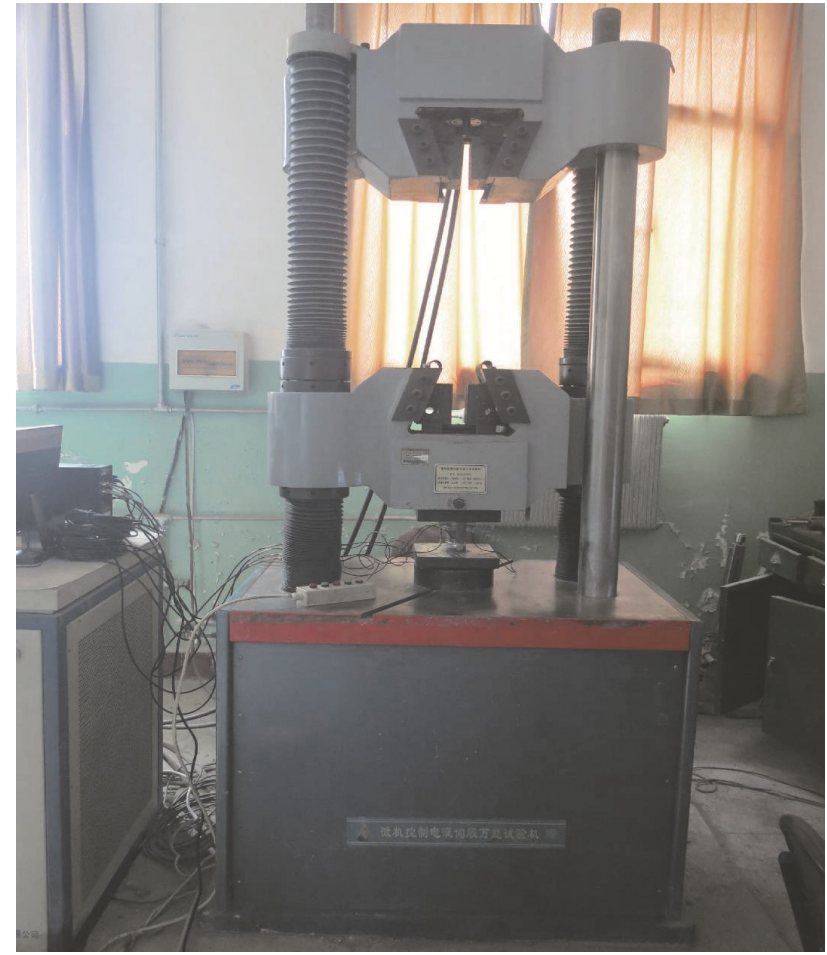

(c)

FIGURE 4: Scheme of the testing system. Micro-II digital AE system (a), position of AE sensors (b), and WAW-1000 conventional mechanical rigid testing machine (c).

31.4\%. The clay minerals interact with water and then soften the rock [39], such as the chlorite, kaolinite, montmorillonite, and illite (Figure 5(d)). These minerals are called "water sensitive minerals." Figures 6(a) and 6(b) unfold the microstructures of lamprophyre in dry state. Some cracks are found in the mineral aggregates. Figures 6(c) and 6(d) reveal the microstructures of lamprophyre in water saturation state. Figure 6(c) demonstrates that the aggregate of orthoclase is usually surrounded by clay minerals. The alterations of the clay minerals under the water-rock interaction improve the extension of crack between orthoclase and clay minerals. The water interactions finally result in the disintegration of mineral aggregates, which is shown in Figure 6(d).

3.2. Water Content. The water content of the rock is calculated by the following equation:

$$
w_{t}=\frac{m_{t}-m_{0}}{m_{0}} \times 100
$$

where $w_{t}$ is the water content of the rock, $m_{t}$ is the weight of the saturated rock, and $m_{0}$ is the weight of the dry rock.

The parameters to calculate the water contents of the specimens in natural temperature immersed saturated and boiled saturated state are shown in Tables 1 and 2, respectively. It is found that the average water contents of the natural temperature immersed saturated and boiled saturated specimens are $0.64 \%$ and $0.89 \%$, respectively.

As shown in Figure 5, the tested hard brittle igneous samples contain cleavage planes (Figure 5(a)) and microvoids
(Figure 5(b)). These planes and voids provide channels for water to enter the inside of rock. Besides that the brittle igneous rock contains some water sensitive minerals [39], such as montmorillonite, chlorite, and illite. The water channels and the water sensitive minerals within the rock promote the water-rock interaction and further increase the inner damage of the igneous rock. The damage is basically divided into three categories [39], the mineral dissolution, expansion, and disintegration. The dissolution and disintegration of the bloedite and orthoclase promote the destruction of the mineral aggregates in lamprophyre; the expansion of the montmorillonite and illite result in the degradation of the lamprophyre specimens. These actions directly break the structural integrity of the mineral aggregate in the rock. In addition, the saturated rock has a higher pore water pressure than the dry rock and the increase of the pore water pressure leads to the decrease of the effective stress, which weakens the elastic modulus and strength of the igneous rock.

3.3. Stress-Strain. Figure 7 shows the strain-stress curves of specimens with different water content from incremental cyclic loading tests. In experiments, rectangular rosettes were used to record the strain data and the $1 \#$ and $2 \#$ strain gauges record the axial and lateral strain, respectively. The comparisons of the axial strain and the loading and unloading displacement for the tested specimens are shown in Figure 8. Though there are some differences, the strain data basically correspond to the loading and unloading displacement. The cycle number in the tests decreases with increase of water 


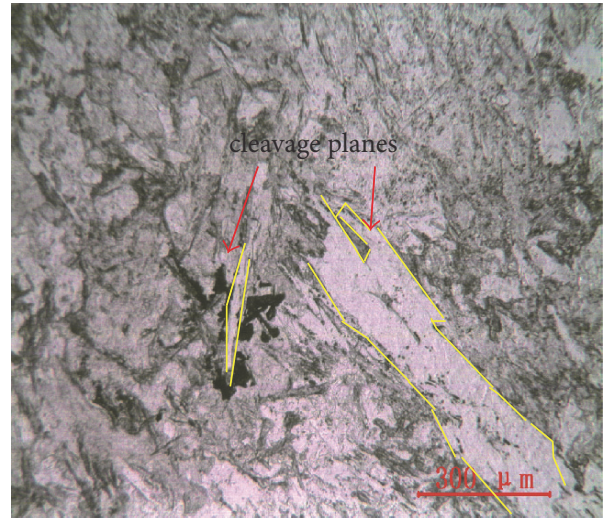

(a)

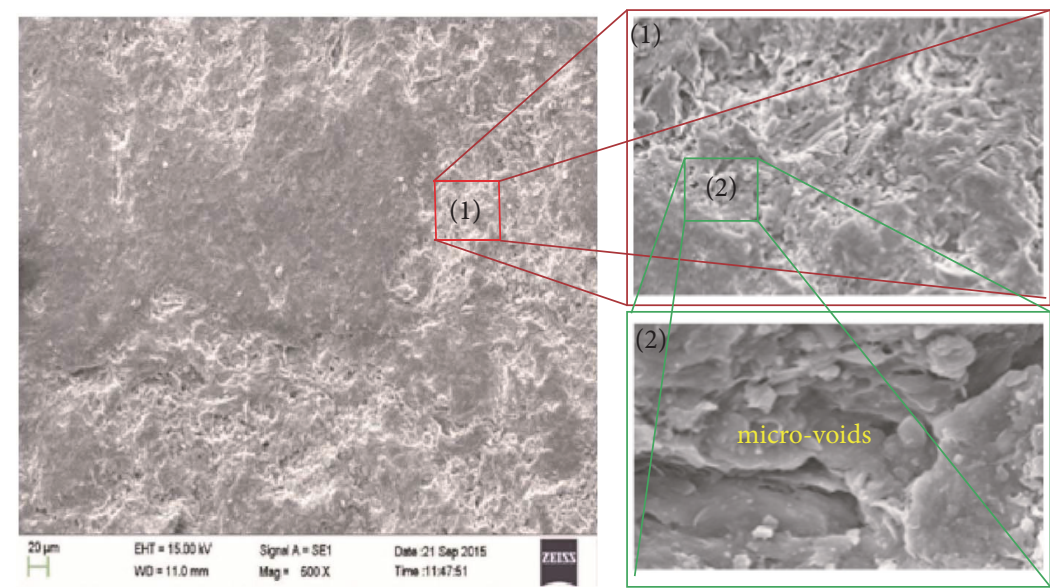

(b)

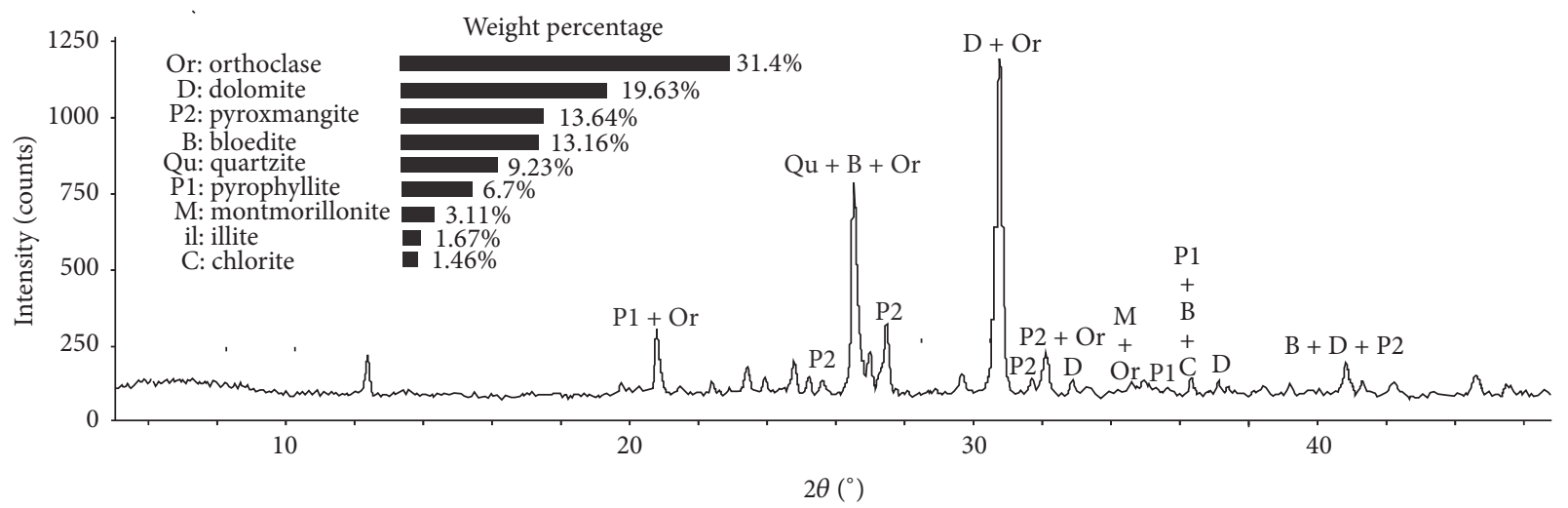

(c)
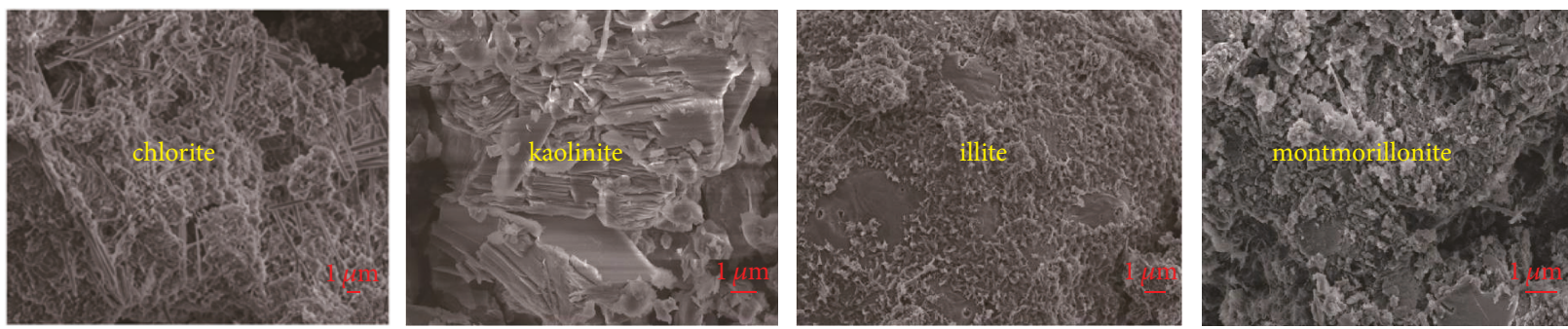

(d)

FIGURE 5: SEM and thin section image of igneous rock sample showing the microstructure (a), (b) and the components analysis of the dry igneous rock based on XRD pattern (c).

TABLE 1: Weight of specimens in natural temperature, immersed saturated, and dry state and their water content.

\begin{tabular}{lcccc}
\hline Specimen & $m_{01} / \mathrm{g}$ & $m_{t 1} / \mathrm{g}$ & $w_{t 1} / \%$ & Average value/\% \\
\hline $4 \#$ & 522.27 & 524.76 & 0.48 & 0.64 \\
$5 \#$ & 535.93 & 539.64 & 0.69 & 0.76 \\
$6 \#$ & 530 & 534 & 0.64 & \\
\hline
\end{tabular}

TABLE 2: Weight of specimens in boiled saturated and dry state and their water content.

\begin{tabular}{lcccc}
\hline Specimen & $m_{02} / \mathrm{g}$ & $m_{t 2} / \mathrm{g}$ & $w_{t 2} / \%$ & Average value/\% \\
\hline $7 \#$ & 529.16 & 533.25 & 0.77 & 0.89 \\
$8 \#$ & 537.14 & 542.73 & 1.04 & 0.86 \\
$9 \#$ & 536.71 & 541.32 & 0.32 & \\
\hline
\end{tabular}




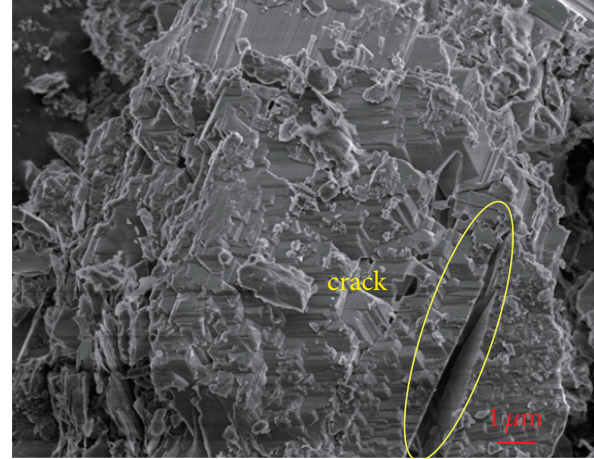

(a)

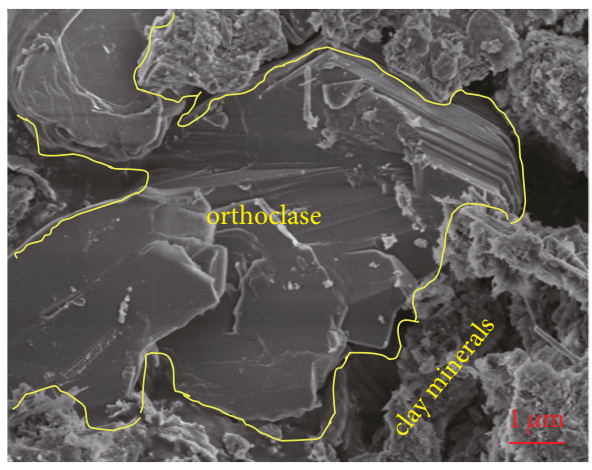

(c)

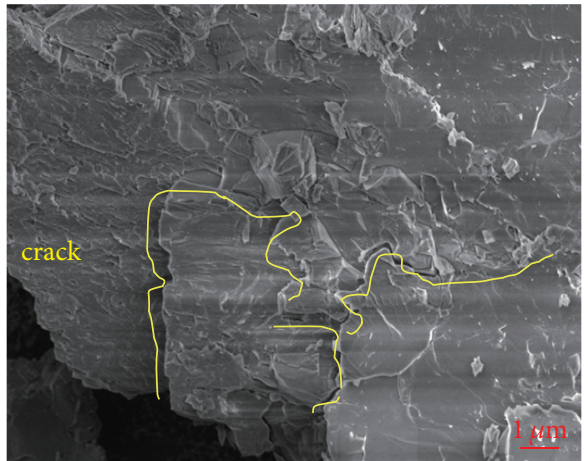

(b)

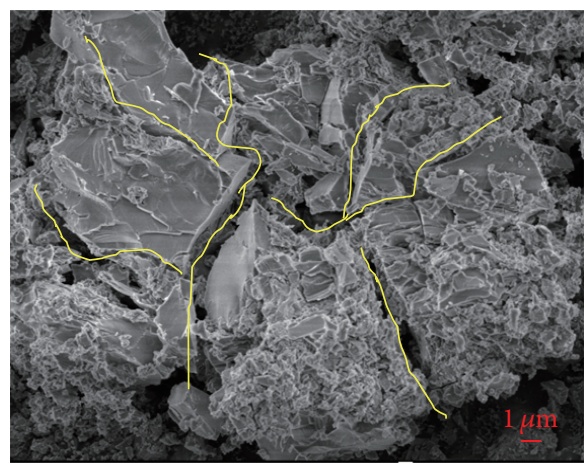

(d)

FIGURE 6: Typical microstructures of the mineral aggregates in lamprophyre.

content and the peak strength of the specimens also decreases obviously. The average peak strength of the dry, the natural water saturated, and the boiled water saturated specimens are $162 \mathrm{MPa}, 128 \mathrm{MPa}$, and $85.4 \mathrm{MPa}$, respectively. The peak strength of the boiled water saturated specimens is just $52.7 \%$ of that of dry specimens. However, the higher the water content a specimen has, the larger the strain the specimen will have under the same stress condition. A plastic hysteresis loop is formed for each cycle, and after each cycle there remains a residual strain which increases from one cycle to another meaning that the sample undergoes inelastic deformation and damage during each cycle.

The differences between the residual strains $\left(\varepsilon_{r}\right)$ and the accumulated strains $\left(\varepsilon_{l}\right)$ of the three groups of water content specimens are plotted in Figure 9 with respect to cycle number. Figure 9(a) indicates that the residual strains $\left(\varepsilon_{r}\right)$ of the specimens in the two types of water saturated states rapidly decrease at the beginning, and then the residual strain $\left(\varepsilon_{r}\right)$ of the natural immersed specimens slowly reaches its minimum value before failure, while the residual strain $\left(\varepsilon_{r}\right)$ of the boiled saturated specimens increases again before failure. As for the dry specimens, the residual strain decreases slowly at the beginning, and then rapidly decreases at the middle, and finally reaches the minimum value before failure. The residual strain in the first cycle of the specimens increases with the increase of the water content. As shown in Figure 9(b), the accumulated residual strain increases with increasing of loading cycles, and the rise speed is more apparent when the specimen is in boiled saturated state.
Figure 9(b) also indicates that the accumulated residual strain increases with increasing of water content, especially for the boiled saturated specimen. The dry specimen shows its hard brittle characteristic in the incremental cyclic loading process. Figure 7 shows that the strength of the dry specimen reaches $162 \mathrm{MPa}$, while small amounts of residual strains (Figure 9) are accumulated during the cyclic loading. Less strains and high strength suggest the hardness and brittleness of the igneous rock. Due to boiling, strength of igneous rock with higher water content is reduced to $85.4 \mathrm{MPa}(52.7 \%$ of the dry specimen); meanwhile, the double residual strains are accumulated compared with the dry specimen. The lower strength and higher strains indicate that the hard brittle characteristic of the igneous rock is weakened with the increase of the water content. Some researchers reported that the hard brittle rock has strong burst proneness [40], which is an important reason of the dynamic disasters in geotechnical engineering. From this aspect, the groundwater can reduce the burst proneness of the igneous rock to some degree. However, the stability of the surrounding rock in the igneous invading area will be influenced by the groundwater, which increases the support difficulty in the field.

3.4. Stress and AE Parameters. AE monitoring has been widely employed as an effective technology to research the damage process of the rock materials [41]. As one of the $\mathrm{AE}$ parameters, $\mathrm{AE}$ count directly reflects the evolution of the plastic failure in the rock [42]. AE energy is a kind of defined energy, which is a parameter related to the amplitude and the 

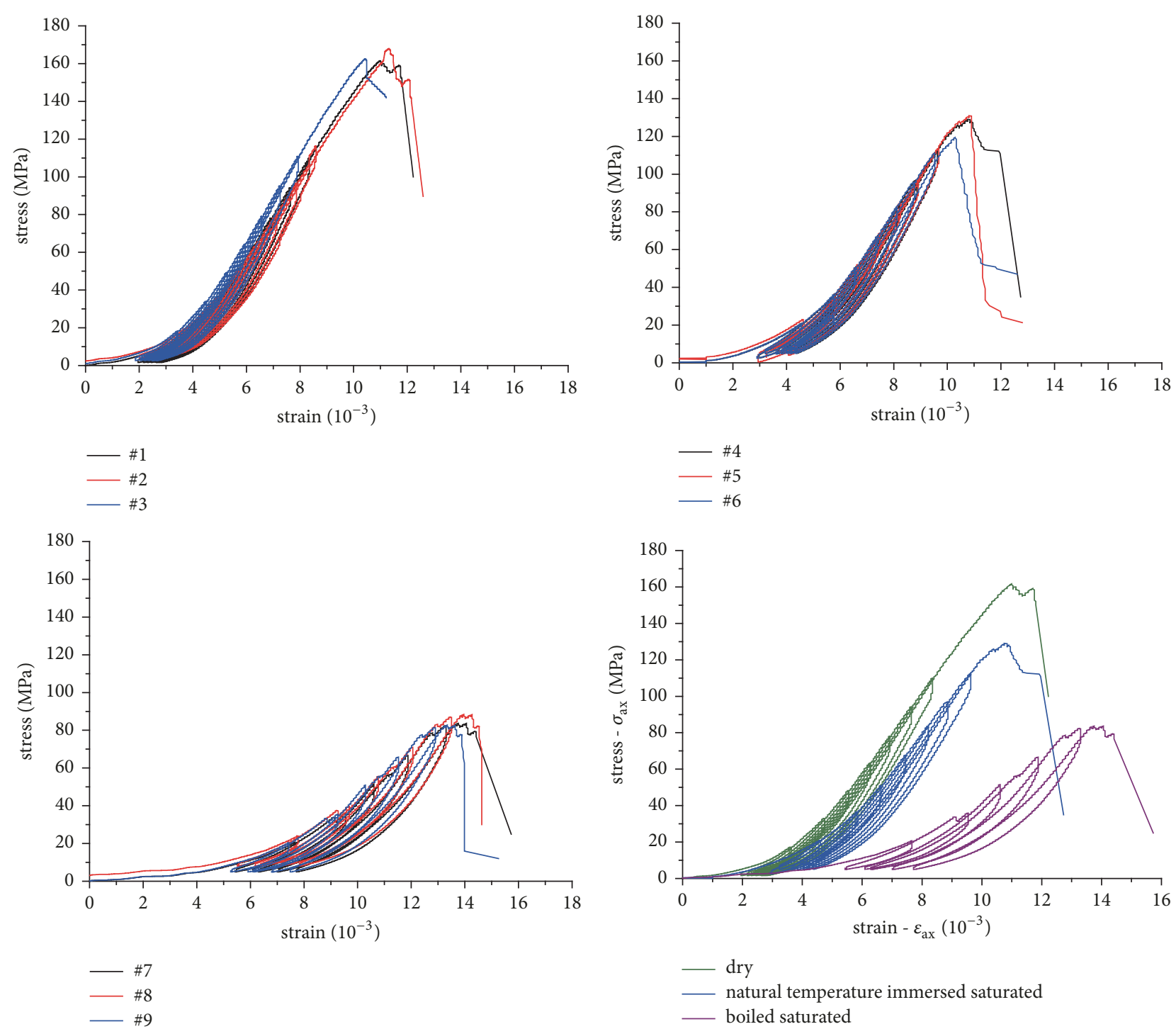

FIGURE 7: Axial stress and strain curves of the different water content samples from incremental cyclic loading tests.

amplitude distribution of the signals. The AE energy is the area under the envelope of signal detection; it only has the mathematical meaning, rather than the actual energy of the acoustic emission signal. Nevertheless, the acoustic emission energy is of great significance for the fracture and damage degree of materials. The cumulative AE energy refers to the cumulative value of AE energy during a sound emission. This parameter describes the total intensity of acoustic emission in the testing progress, which is the process parameter, and is also the external performance of the change of the internal structure of the material. The laws of the AE count, cumulative $\mathrm{AE}$ energy, and the axial stress in function with time can describe the fatigue feature of the rock subjected to cyclic load. Figure 10 shows that the AE count and stress of the tested three duplicates are basically same in each group. The comparisons of $\mathrm{AE}$ count and accumulated AE energy for three specimens with different water contents are shown in Figure 11. Figure 11(a) shows that the number of AEs slowly increases in the former seven cycles, while it rapidly increases in the eighth cycle; meanwhile, a large amount of cumulative $\mathrm{AE}$ energy is concentrated in the peak stage of stress. These results indicate that the plastic failures of the dry igneous rock suddenly occur at a high stress level and the stored energy is suddenly released, which fully reflects the hard and brittle behavior and the strong burst proneness of the igneous rock. Therefore, more attention should be paid to the potential dynamic disasters induced by the rock burst of the igneous rock in the deep mining engineering. The AE features of the water saturated igneous rock are significantly different than the dry rock. Figure 11(b) shows that the numbers of AEs of the natural water saturated specimen are more concentrated in the former loading cycles. The cumulative $\mathrm{AE}$ energy is stepwise increased and a relatively larger step of $\mathrm{AE}$ accumulated energy is produced at a lower stress level during the loading process. These mean that the plastic failures of the water saturated igneous rock are contiguously extended and the igneous rock lost its burst proneness under the waterrock interaction. The concentrated $\mathrm{AE}$ count in the former 


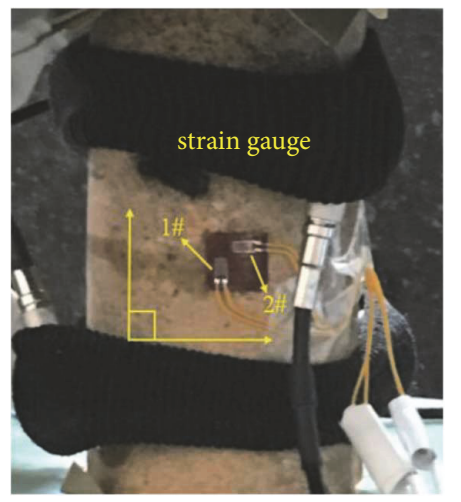

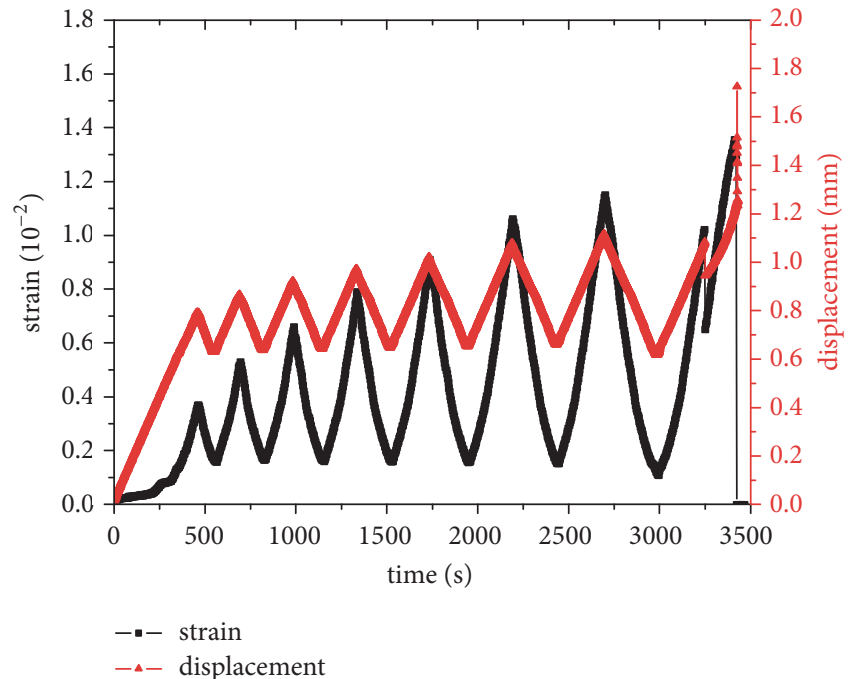

(a) Dry specimen

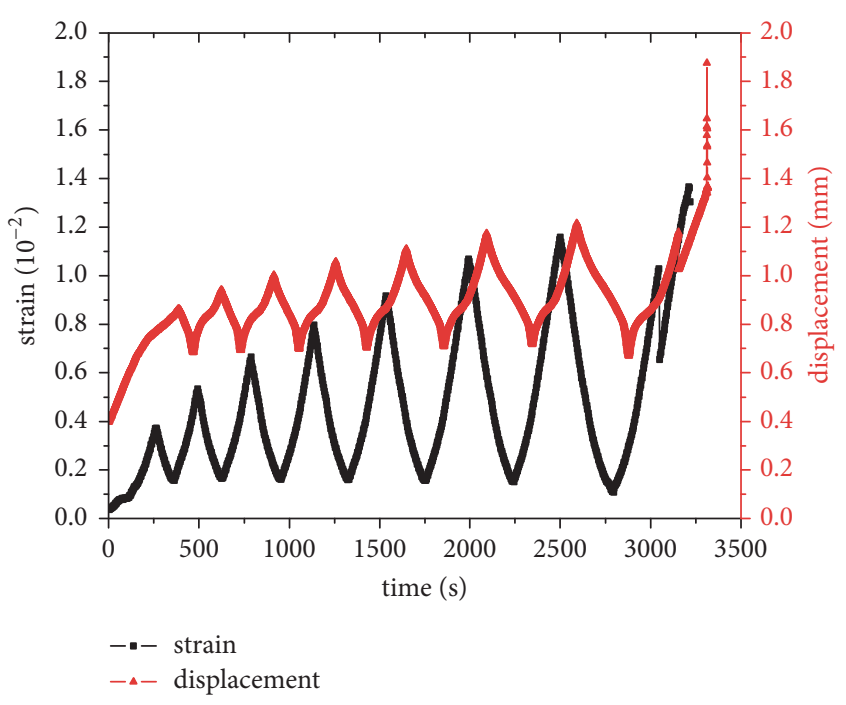

(b) Nature water-saturated specimen

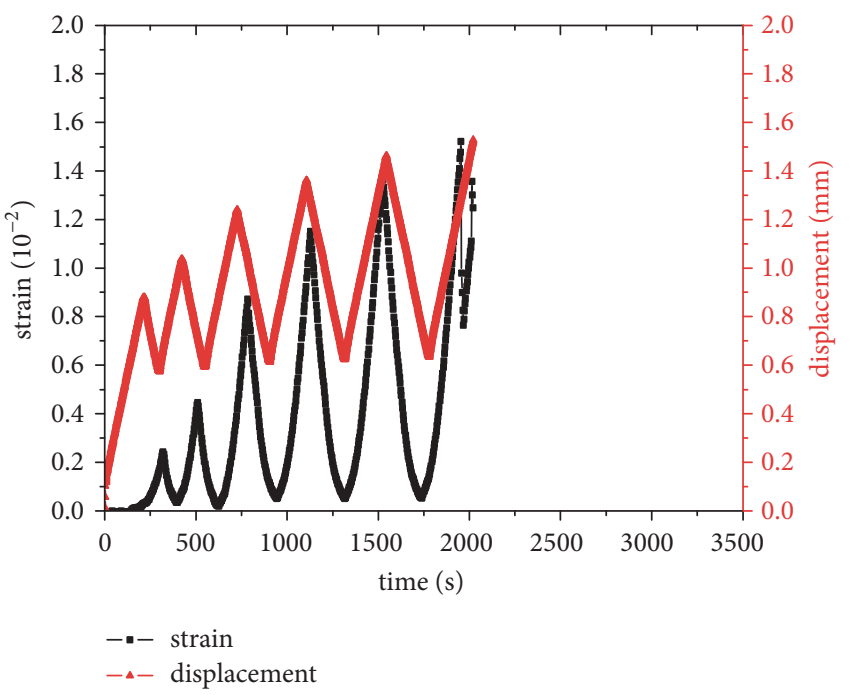

(c) Boiled saturated specimen

FIGURE 8: Direction and location of strain gauge. Strain data and loading and unloading displacement of different water content specimens with time. 


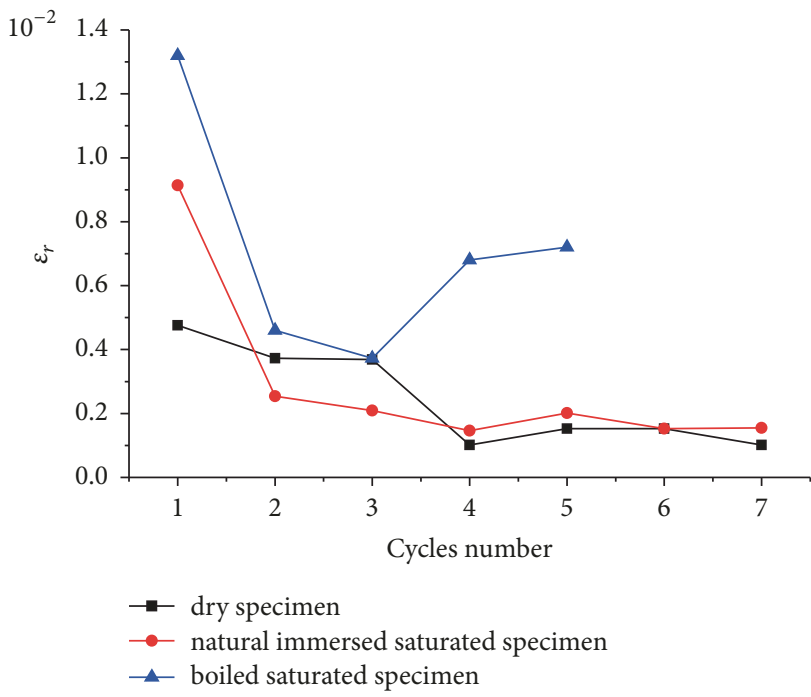

(a)

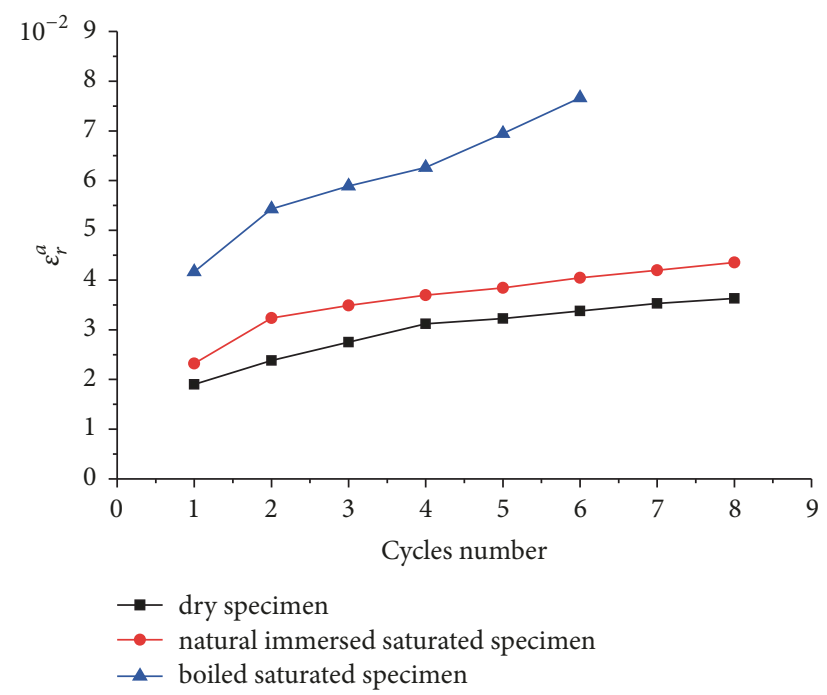

(b)

FIGURE 9: Residual strains of the three specimens in each loading cycle. Residual nominal strain (a) and the accumulated residual strain (b).

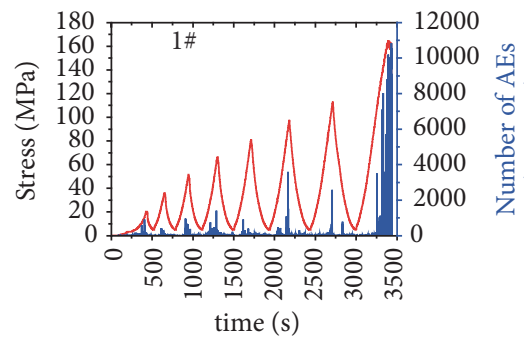

- time-stress

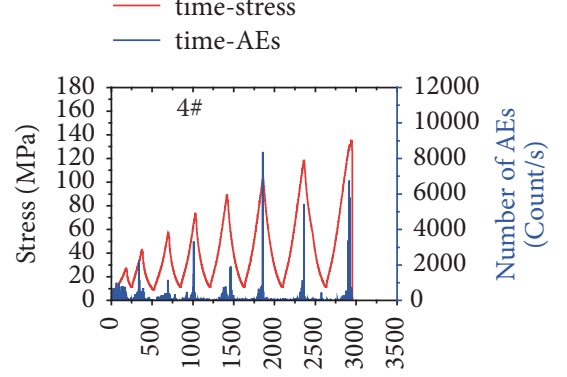

time (s)

- time-stress

— time-AEs

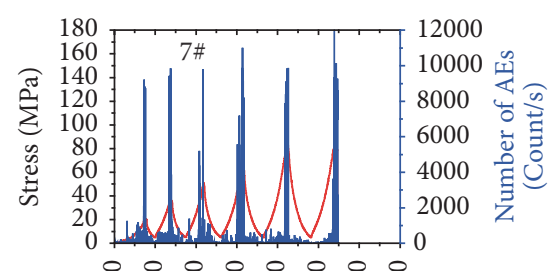

○ \&

time (s)

- time-stress

— time-AEs
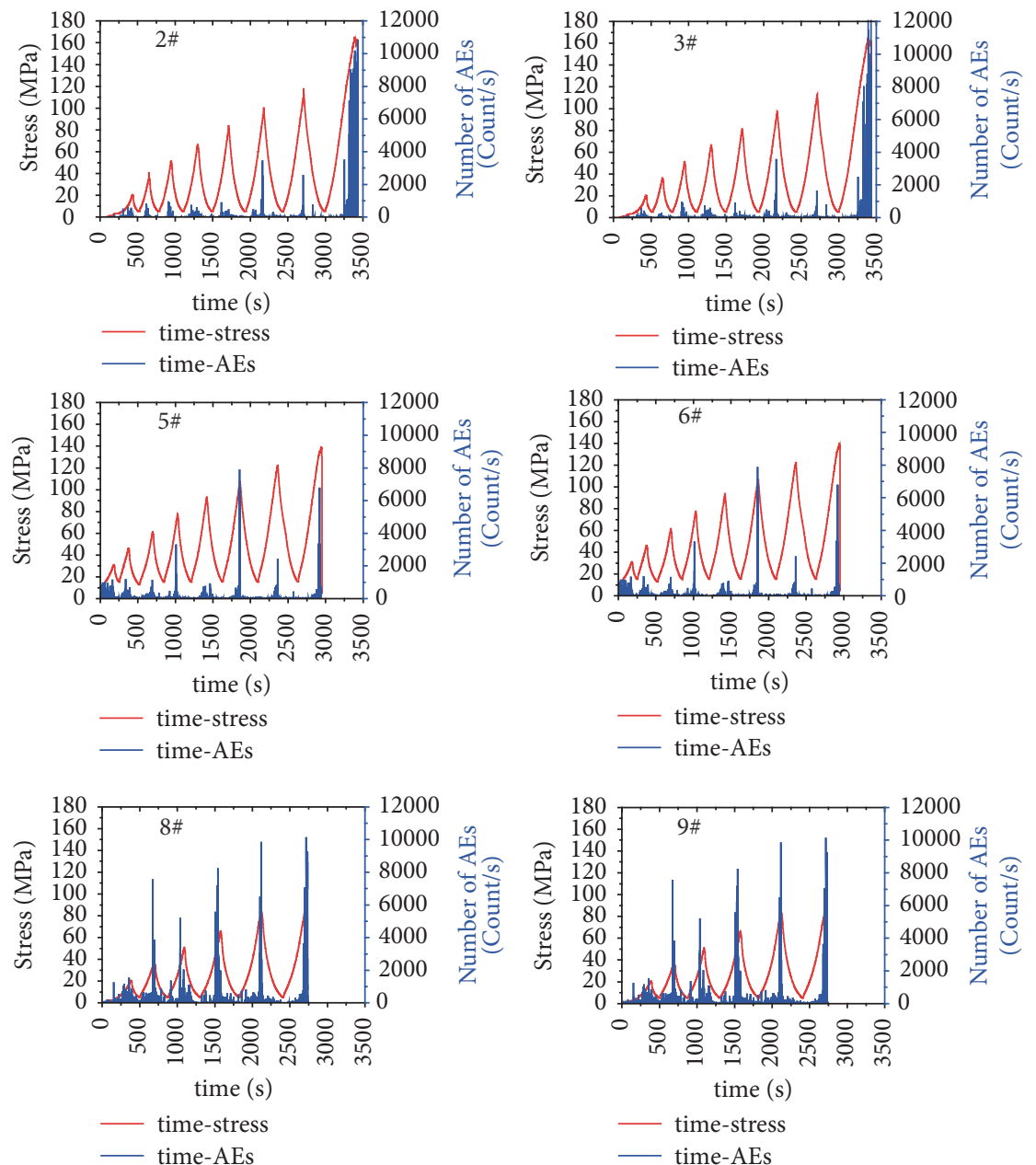

FIGURE 10: AE counts and stress of the tested specimens versus time. 

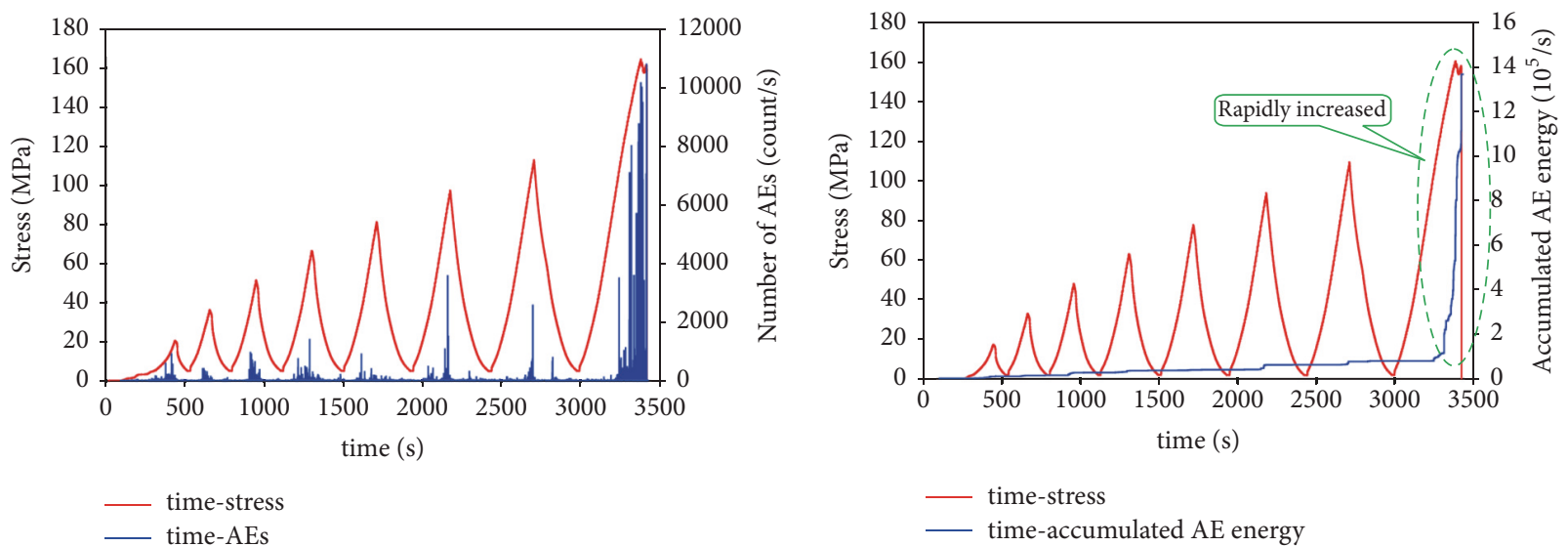

(a) Dry specimen 2\#
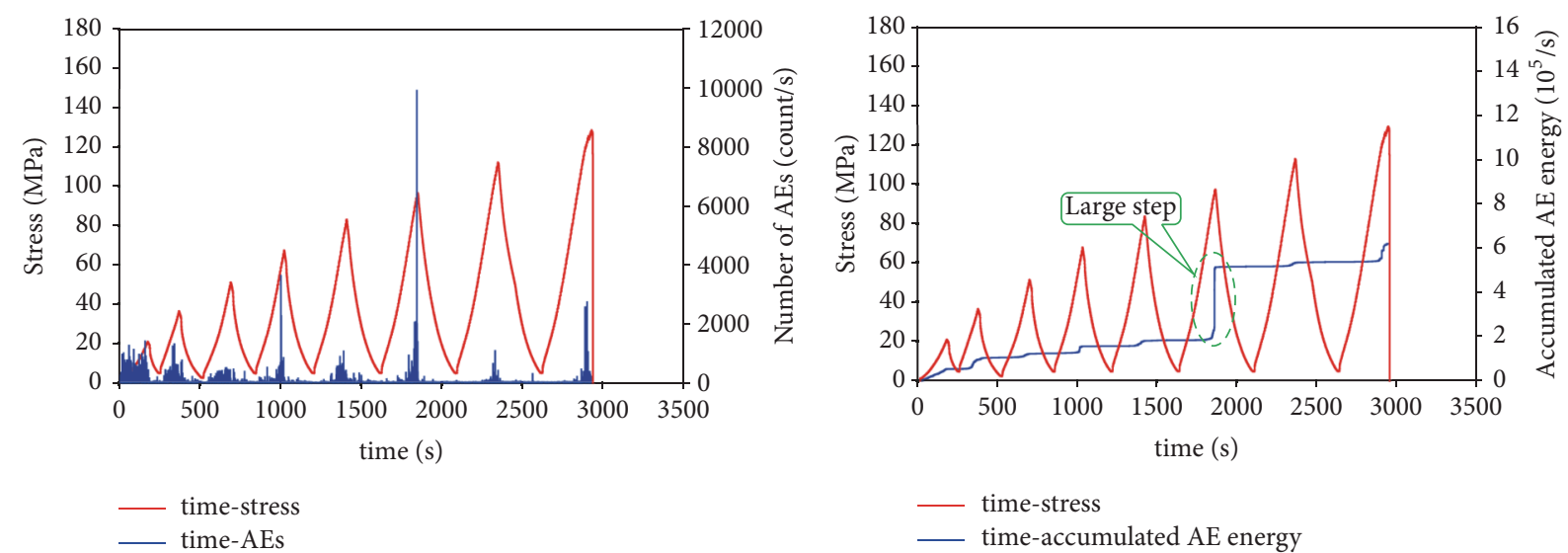

(b) Nature water saturated specimen 5\#
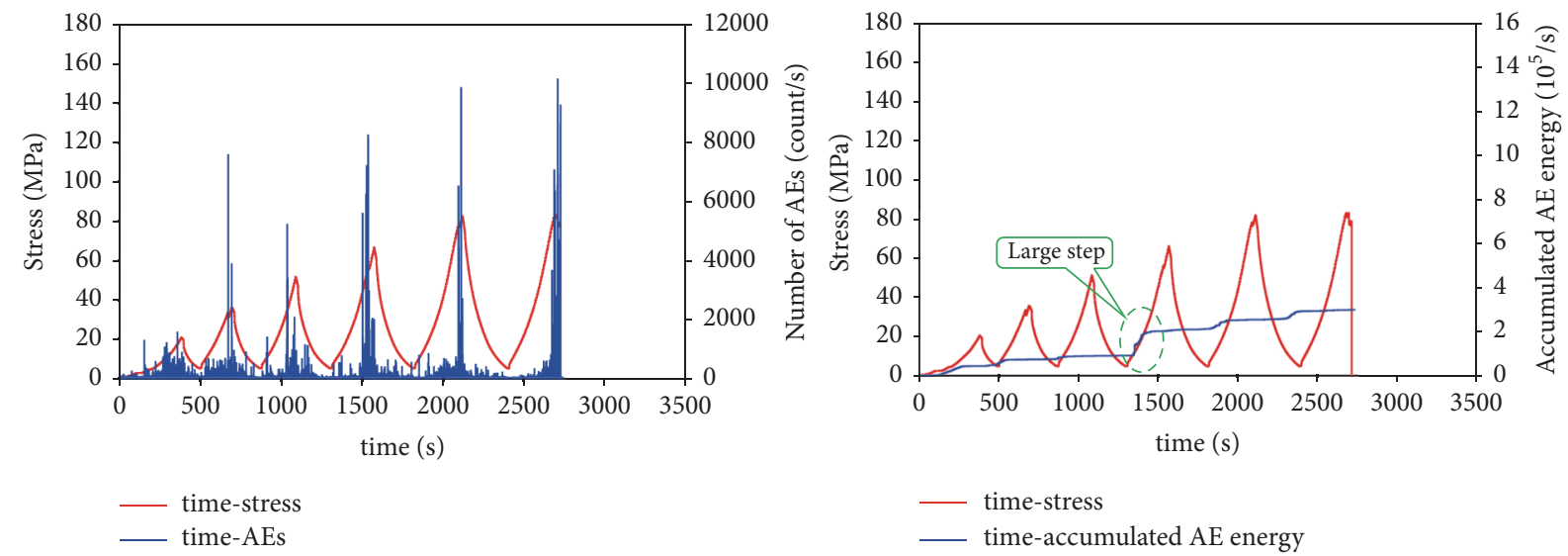

(c) Boiled saturated rock $8 \#$

Figure 11: Comparison between the axial stress, cumulative AE energy, and AE counts with time of specimens with different water content Felicity Ratio.

loading cycles of the natural water saturated specimen reflects that the water-rock interaction improves the development of the damage in the igneous rock. Figure 11(c) shows that the numbers of the AEs of the boiled water saturated specimen uniformly occurred during both the loading and unloading of each cycle and the cumulated AE energy also increases stepwise. During the loading, the axial deformations of the rock specimen are its macroresponse to its accumulated intrinsic microdamage and cracking. Water-rock interaction promotes the development of the microdamage and cracking, which can be proved by the active AEs responses for the specimens with higher water content. The AE counts that occurred during both loading and unloading reflect dramatic plastic feature of the specimen. The igneous rock completely 
loses its burst proneness under the actions of the water. The $\mathrm{AE}$ count can reflect the real-time microfracture actions; the higher AE count represents the specimen being in high damage state. Compared with the dry specimens, the AE count of the boiled saturated specimens reaches high levels in its all loading cycles, which proves that the higher the water content of the igneous rock is, the easier it is to enter the high damage state. The peak stresses of the three different water content specimens are $162 \mathrm{MPa}, 128 \mathrm{MPa}$, and $85.4 \mathrm{MPa}$, respectively. Obviously, the peak stress of the specimens decreases with the increase of their water content. These results proved that the water can obviously change the properties of the igneous rock, especially under the dynamic loading and unloading process. Effective measures should be taken based on a comprehension of the hydrogeological conditions of a filed mining project in igneous intrusion area.

3.5. Felicity Ratio. The phenomenon that acoustic emission only starts when the stress exceeds the previously applied stress is called Kaiser Effect (KE), which was first propounded by Dr. Joseph Kaiser in his doctoral dissertation in 1950 [43]. Another phenomenon is that a significant acoustic emission might be generated before the previous maximum load was reached in the cyclic process, which was discovered and defined as Felicity Effect (FE) by Fowler in the 80s. Based on the principles of the KE and FE, Felicity Ratio (FR) was defined to describe the damage state of the material quantitatively. Researchers concluded that the higher the FR is, the lower the damage state is. In other words, a high FR value $(\mathrm{FR}>1)$ is linked to low damage state, while the lower FR value $(F R<1)$ is related to high damage state. In this paper the FR is defined as (2) to show the damage state of the specimens with different water contents.

$$
F=\frac{P_{1}}{P_{2}},
$$

where $P_{1}$ is the stress corresponding to the significant acoustic emission that occurred in the repeated loading process; $P_{2}$ is the maximum stress in the former loading process.

Considering the changes of properties of the rock specimens caused by water-rock interaction and a fixed threshold in the experiments, the numbers of $\mathrm{AE}$ event or $\mathrm{AE}$ count are not suitable for determining the "the significant $\mathrm{AE}$ occurred" time in the present paper. In order to find the "the significant AE occurred" time, take the results of natural water saturated specimens as an example; the relationship between the accumulative count and stress with time is presented in Figure 12.

We take the time when the obvious inflection point occurred in the cumulative acoustic AE count curve as the "the significant AE occurred" time (Figure 12). Based on (2) and the stress, $\mathrm{AE}$ count data of specimens with different water contents, the FR, and the initial time of the $\mathrm{AE}$ counts in each cycle are listed in Table 3. Figure 13 shows the FR of specimens with different water contents with respect to time. Overall, the FR of the specimen decreases with the increase of the time. In practical terms, the FR of the dry specimen in

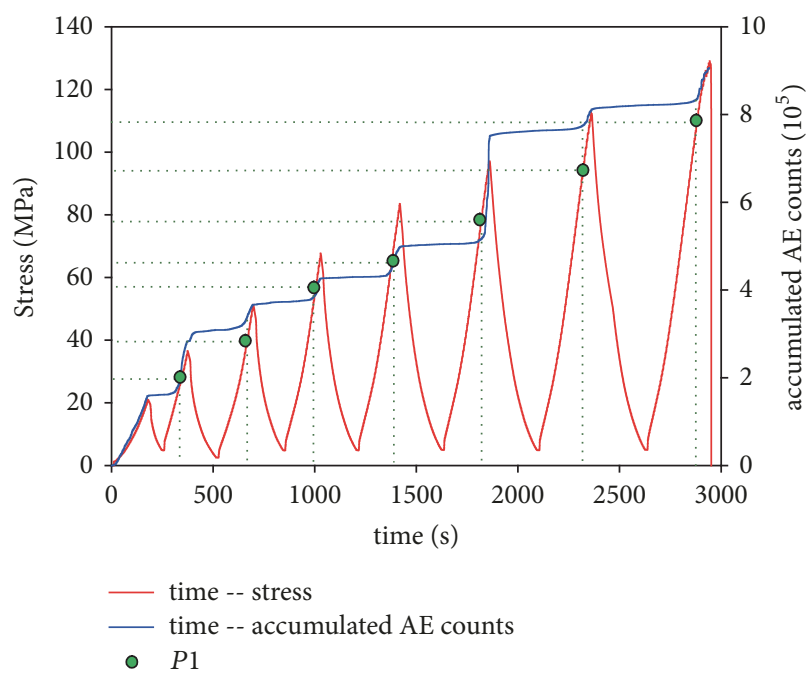

FIgURE 12: The stress corresponding to the significant acoustic emission that occurred in the repeated loading process.

the first six cycles is larger than 1.0 and less than 1.0 in the last cycle. As for the natural water saturated specimen, the FR is larger than 1.0 in the first three cycles and less than 1.0 in the later three cycles. The FR of the boiled saturated specimen is larger than 1.0 only in the first cycle and then less than 1.0 in the later cycles. Basically, the brittle igneous rock presents the FE earlier with higher water content. In other words, the higher the water content of igneous rock is, the more easily it is to enter the high damage state.

\section{Conclusions}

The fewer accumulated residual strains, abrupt occurrence of a large amount of $\mathrm{AE}$ counts, and rapidly increased $\mathrm{AE}$ energy at high peak stress stage in the uniaxial cyclic loading and unloading process of the dry igneous rock reflect its hard brittle characteristic and strong burst proneness. Thus, more attention should be paid to the potential dynamic disasters induced by the rock burst of the igneous rock in the deep mining engineering.

The average peak strengths of the dry, the natural water saturated, and the boiled water saturated specimens are $162 \mathrm{MPa}, 128 \mathrm{MPa}$, and $85.4 \mathrm{MPa}$, respectively. With the increase of the water content, the strength of igneous rock decreases obviously. The natural water saturated and boiled saturated rocks present lower peak strength, more residual strains, and the stepwise increased $\mathrm{AE}$ energy during the cyclic loading and unloading process. The Felicity Ratios of igneous samples with different water contents further conclude that the water-rock interaction promotes the igneous rock into the high damage state. These results suggest that the water injection method is a feasible method that can be used to soften the igneous rock and to prevent the dynamic disasters within roadways and working faces located in the igneous intrusion area.

The cleavage planes and microvoids of the igneous rock provide the channels for water to enter the inside of the rock. 
TABLE 3: Felicity Ratio and initial time of the AE counts in each cycle of specimens with different water contents.

\begin{tabular}{lccccccc}
\hline Cycle number & 2 & 3 & 4 & 5 & 6 & 7 & 8 \\
\hline Dry & 1.143 & 1.09 & 1.042 & 1.03 & 1.03 & 1.02 & 0.97 \\
time/s & 587 & 923 & 1260 & 1660 & 2141 & 2654 & 3263 \\
\hline Natural water-saturated & 1.19 & 1.03 & 1.02 & 0.9 & 0.87 & 0.93 \\
Time/s & 300 & 623 & 1000 & 1400 & 1822 & 2320 & 2878 \\
\hline Boiled-saturated & 1.13 & 1 & 0.98 & 0.85 & 0.83 & - \\
Time/s & 464 & 873 & 1451 & 2053 & 2604 & - \\
\hline
\end{tabular}
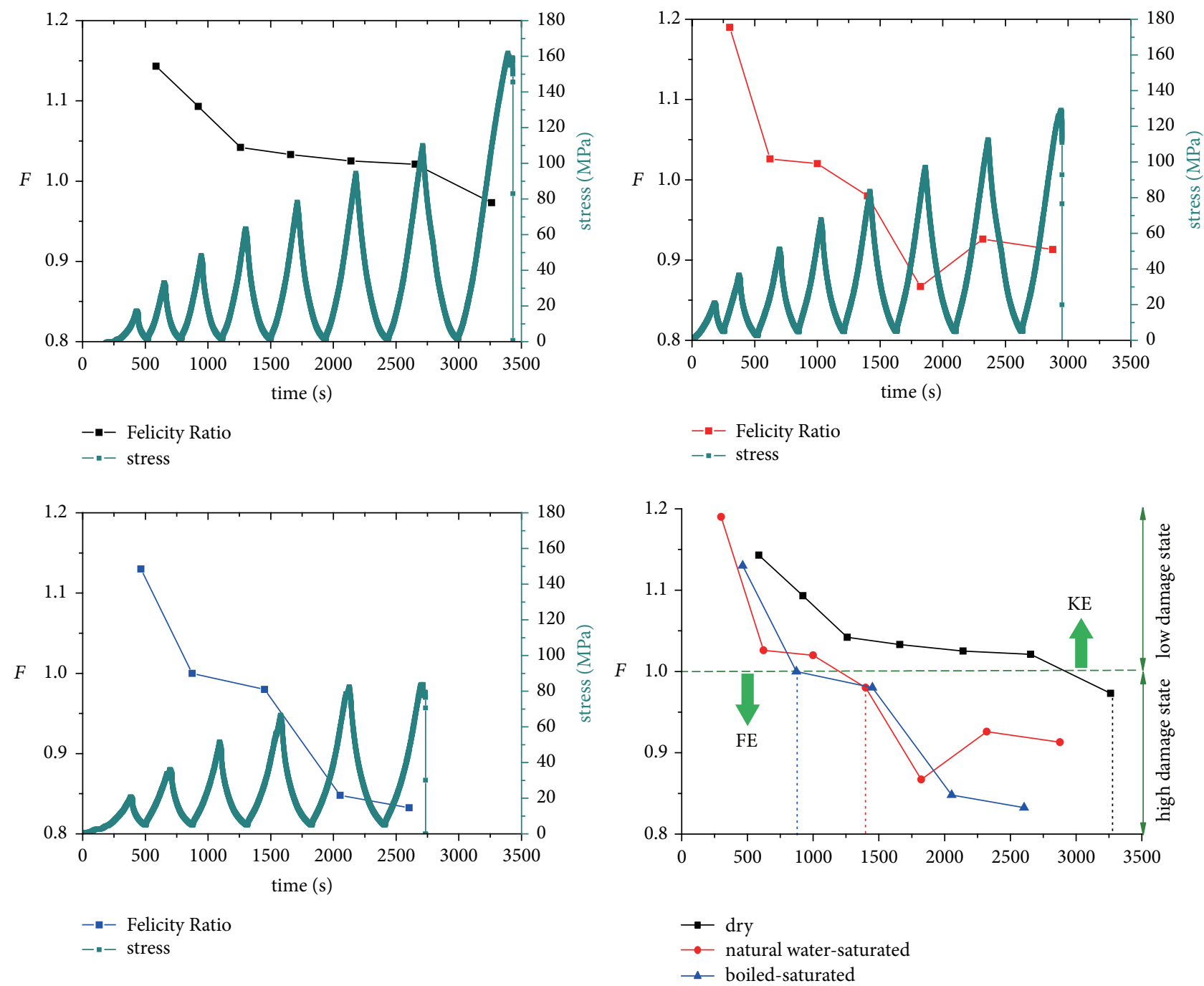

FIGURE 13: Felicity Ratio and stress of the different water content specimens in function with time. KE refers to the Kaiser Effect; FE refers to Felicity Effect.

The researched igneous rock mainly contains the orthoclase, dolomite, pyroxmangite, bloedite, quartzite, and some clay minerals. The content of the orthoclase reaches $31.4 \%$. The orthoclase and clay minerals constitute the mineral aggregate of igneous rock. The cyclic loading and unloading increase the dislocation between the mineral aggregates and waterrock interaction further breaks the adhesion of the clay minerals, which jointly promote the inner damage of the igneous rock.

\section{Conflicts of Interest}

The authors declare that they have no conflicts of interest.

\section{Acknowledgments}

Financial support from the National Science Fund for Excellent Young Scholars (no. 51422404), the National Natural Science Foundation of China (no. 51174142, 51574172), the Key Scientific and Technological Coal Projects of Shanxi 
Province in 2014 (MQ2014-12), and Youth Fund Project for Applied Basic Research of Shanxi (no. 201601D021089) is greatly appreciated. The authors are grateful to Datong Coal Ground Corporation Limited for providing field testing.

\section{References}

[1] R. Singh, A. Singh, and P. Mandal, "Cuttability of coal seams with igneous intrusions," Engineering Geology, vol. 67, no. 1-2, pp. 127-137, 2002.

[2] R. E. Ernst, A. V. Okrugin, R. V. Veselovskiy et al., “The 1501 Ma Kuonamka Large Igneous Province of northern Siberia: U$\mathrm{Pb}$ geochronology, geochemistry, and links with coeval magmatism on other crustal blocks," Russian Geology and Geophysics, vol. 57, no. 5, pp. 653-671, 2016.

[3] G. M. Airoldi, J. D. Muirhead, S. M. Long, E. Zanella, and J. D. L. White, "Flow dynamics in mid-Jurassic dikes and sills of the Ferrar large igneous province and implications for longdistance magma transport," Tectonophysics, vol. 683, pp. 182199, 2016.

[4] Y. Yao, D. Liu, and W. Huang, "Influences of igneous intrusions on coal rank, coal quality and adsorption capacity in Hongyang, Handan and Huaibei coalfields, North China," International Journal of Coal Geology, vol. 88, no. 2-3, pp. 135-146, 2011.

[5] L. Wang, Y. Cheng, Y. Yang et al., "Controlling the effect of a distant extremely thick igneous rock in overlying strata on coal mine disasters," Mining Science and Technology, vol. 20, no. 4, pp. 510-515, 2010.

[6] L. Wang, L.-B. Cheng, Y.-P. Cheng et al., "Characteristics and evolutions of gas dynamic disaster under igneous intrusions and its control technologies," Journal of Natural Gas Science and Engineering, vol. 18, pp. 164-174, 2014.

[7] J. Chen, G. Liu, H. Li, and B. Wu, "Mineralogical and geochemical responses of coal to igneous intrusion in the Pansan Coal Mine of the Huainan coalfield, Anhui, China," International Journal of Coal Geology, vol. 124, pp. 11-35, 2014.

[8] X.-L. Zhang, Y.-P. Cheng, L. Wang, and W. Zhao, "Research on the controlling effects of a layered sill with different thicknesses on the underlying coal seam gas occurrence," Journal of Natural Gas Science and Engineering, vol. 22, pp. 406-414, 2015.

[9] C.-P. Lu, Y. Liu, H.-Y. Wang, and P.-F. Liu, "Microseismic signals of double-layer hard and thick igneous strata separation and fracturing," International Journal of Coal Geology, vol. 160-161, pp. 28-41, 2016.

[10] D. Xuan, J. Xu, and W. Zhu, "Dynamic disaster control under a massive igneous sill by grouting from surface boreholes," International Journal of Rock Mechanics and Mining Sciences, vol. 71, pp. 176-187, 2014.

[11] J. Xu, J. Jiang, L. Zuo, and Y. Gao, "Acoustic Emission Monitoring and Failure Precursors of Sandstone Samples under Various Loading and Unloading Paths," Shock and Vibration, vol. 2017, pp. 1-11, 2017.

[12] M. M. Sherif, J. Tanks, and O. E. Ozbulut, "Acoustic emission analysis of cyclically loaded superelastic shape memory alloy fiber reinforced mortar beams," Cement and Concrete Research, vol. 95, pp. 178-187, 2017.

[13] C. M. Sauerbrunn, A. Kahirdeh, H. Yun, and M. Modarres, "Damage assessment using information entropy of individual acoustic emission waveforms during cyclic fatigue loading," Applied Sciences (Switzerland), vol. 7, no. 6, article no. 562, 2017.
[14] H. Toyama, H. Kishida, and A. Yonezu, "Characterization of fatigue crack growth of concrete mortar under cyclic indentation loading," Engineering Failure Analysis, vol. 83, pp. 156-166, 2018.

[15] A. Chilali, W. Zouari, M. Assarar, H. Kebir, and R. Ayad, "Effect of water ageing on the load-unload cyclic behaviour of flax fibre-reinforced thermoplastic and thermosetting composites," Composite Structures, vol. 183, no. 1, pp. 309-319, 2017.

[16] J. Browning, P. G. Meredith, C. E. Stuart, D. Healy, S. Harland, and T. M. Mitchell, "Acoustic characterization of crack damage evolution in sandstone deformed under conventional and true triaxial loading," Journal of Geophysical Research: Solid Earth, vol. 122, no. 6, pp. 4395-4412, 2017.

[17] F. Trippetta, C. Collettini, P. G. Meredith, and S. Vinciguerra, "Evolution of the elastic moduli of seismogenic Triassic Evaporites subjected to cyclic stressing," Tectonophysics, vol. 592, pp. 67-79, 2013.

[18] J. A. Wang and H. D. Park, "Comprehensive prediction of rockburst based on analysis of strain energy in rocks," Tunnelling and Underground Space Technology, vol. 16, pp. 49-57, 2001.

[19] J. Fan, J. Chen, D. Jiang, A. Chemenda, J. Chen, and J. Ambre, "Discontinuous cyclic loading tests of salt with acoustic emission monitoring," International Journal of Fatigue, vol. 94, pp. 140-144, 2017.

[20] J. Yue, "Damage prediction in RC columns under low-cyclic loading using AE monitoring technique," Soil Dynamics and Earthquake Engineering, vol. 78, pp. 110-115, 2015.

[21] M. C. He, J. L. Miao, and J. L. Feng, "International Journal of Rock Mechanics \& Mining Sciences Rock burst process of limestone and its acoustic emission characteristics under truetriaxial unloading conditions," International Journal of Rock Mechanics and Mining Sciences, vol. 47, pp. 286-298, 2010.

[22] Y.-L. Tan, W.-Y. Guo, Q.-H. Gu et al., "Research on the Rockburst Tendency and AE Characteristics of Inhomogeneous Coal-Rock Combination Bodies," Shock and Vibration, vol. 2016, Article ID 9271434, 2016.

[23] A. Lavrov, "The Kaiser effect in rocks: principles and stress estimation techniques," International Journal of Rock Mechanics and Mining Sciences, vol. 40, no. 2, pp. 151-171, 2003.

[24] C. Li and E. Nordlund, "Experimental verification of the Kaiser effect in rocks," Rock Mechanics and Rock Engineering, vol. 26, no. 4, pp. 333-351, 1993.

[25] Z. Chen, L. Tham, and H. Xie, "Experimental and numerical study of the directional dependency of the Kaiser effect in granite," International Journal of Rock Mechanics and Mining Sciences, vol. 44, no. 7, pp. 1053-1061, 2007.

[26] A. Lavrov, "Kaiser effect observation in brittle rock cyclically loaded with different loading rates," Mechanics of Materials, vol. 33, no. 11, pp. 669-677, 2001.

[27] L. Dong, D. Sun, X. Li, and K. Du, “Theoretical and Experimental Studies of Localization Methodology for AE and Microseismic Sources Without Pre-Measured Wave Velocity in Mines," IEEE Access, vol. 5, pp. 16818-16828, 2017.

[28] L. Dong, J. Wesseloo, Y. Potvin, and X. Li, "Discriminant models of blasts and seismic events in mine seismology," International Journal of Rock Mechanics and Mining Sciences, vol. 49, no. 1, pp. 282-291, 2016.

[29] L. Dong, W. Shu, G. Han, X. Li, and J. Wang, "A Multi-Step Source Localization Method with Narrowing Velocity Interval of Cyber-Physical Systems in Buildings," IEEE Access, vol. 5, pp. 20207-20219, 2017. 
[30] B. Vásárhelyi, "Statistical analysis of the influence of water content on the strength of the miocene limestone," Rock Mechanics and Rock Engineering, vol. 38, no. 1, pp. 69-76, 2005.

[31] D. Li, L. N. Y. Wong, G. Liu, and X. Zhang, "Influence of water content and anisotropy on the strength and deformability of low porosity meta-sedimentary rocks under triaxial compression," Engineering Geology, vol. 126, pp. 46-66, 2012.

[32] E. Kim, M. A. Stine, D. B. M. de Oliveira, and H. Changani, "Correlations between the physical and mechanical properties of sandstones with changes of water content and loading rates," International Journal of Rock Mechanics and Mining Sciences, vol. 100, pp. 255-262, 2017.

[33] J. Fukuda, J. Muto, and H. Nagahama, "Strain localization and fabric development in polycrystalline anorthite + melt by water diffusion in an axial deformation experiment," Earth, Planets and Space, vol. 70, no. 1, 2018.

[34] G. R. Lashkaripour, A. Rastegarnia, and M. Ghafoori, "Assessment of brittleness and empirical correlations between physical and mechanical parameters of the Asmari limestone in Khersan 2 dam site, in southwest of Iran," Journal of African Earth Sciences, vol. 138, pp. 124-132, 2018.

[35] G.-C. Li, C.-C. Qi, Y.-T. Sun, X.-L. Tang, and B.-Q. Hou, "Experimental Study on the Softening Characteristics of Sandstone and Mudstone in Relation to Moisture Content," Shock and Vibration, vol. 2017, Article ID 4010376, 2017.

[36] X. Lei, T. Tamagawa, K. Tezuka, and M. Takahashi, "Role of drainage conditions in deformation and fracture of porous rocks under triaxial compression in the laboratory," Geophysical Research Letters, vol. 38, no. 24, Article ID L24310, 2011.

[37] B. Vásárhelyi and P. Ván, "Influence of water content on the strength of rock," Engineering Geology, vol. 84, no. 1-2, pp. 7074, 2006.

[38] B. Vasarhelyi, "Some observations regarding the strength and deformability of sandstones in dry and saturated conditions," Bulletin of Engineering Geology and the Environment, vol. 62, no. 3, pp. 245-249, 2003.

[39] J. Guo, G. Feng, Y. Guo, T. Qi, Y. Zhang, and A. Ren, Mechanical property variation under dynamic uniaxial compression and mechanism of lamprophyre in saturated state, vol. 40, 2015.

[40] X. Feng, E. Wang, R. Shen, M. Wei, Y. Chen, and X. Cao, "The dynamic impact of rock burst induced by the fracture of the thick and hard key stratum," Procedia Eng, vol. 26, pp. 457-465, 2011.

[41] Z. Zhang, E. Wang, D. Chen, X. Li, and N. Li, “The observation of $\mathrm{AE}$ events under uniaxial compression and the quantitative relationship between the anisotropy index and the main failure plane," Journal of Applied Geophysics, vol. 134, pp. 183-190, 2016.

[42] S. Wu, H. Ge, X. Wang, and F. Meng, "Shale failure processes and spatial distribution of fractures obtained by AE monitoring," Journal of Natural Gas Science and Engineering, vol. 41, pp. 8292, 2017.

[43] A. Lehtonen, J. W. Cosgrove, J. A. Hudson, and E. Johansson, "An examination of in situ rock stress estimation using the Kaiser effect," Engineering Geology, vol. 124, no. 1, pp. 24-37, 2012. 


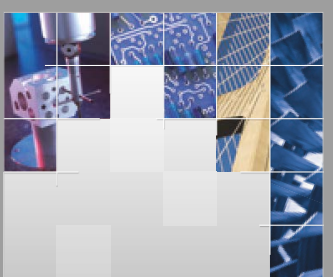

\section{Enfincering}
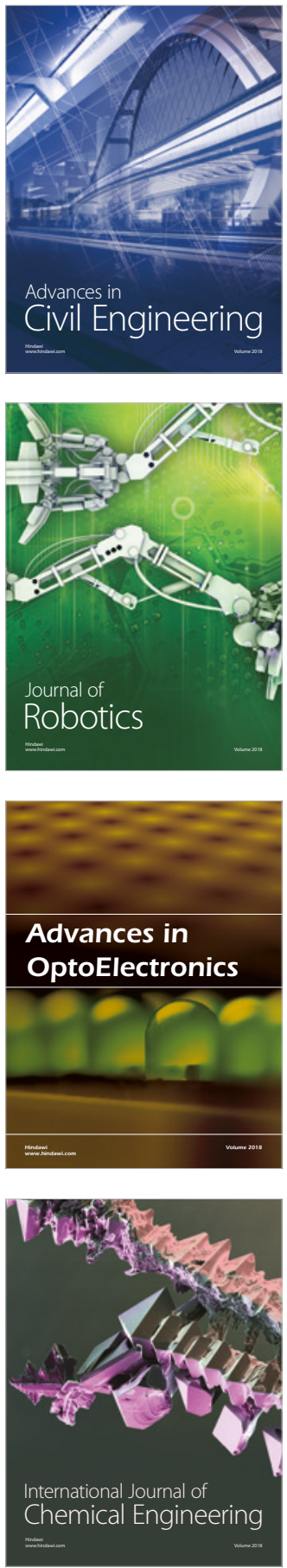

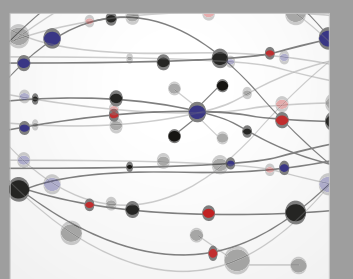

\section{Rotating \\ Machinery}

The Scientific World Journal

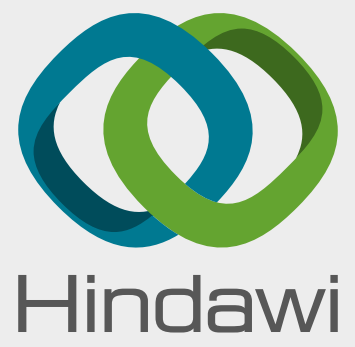

Submit your manuscripts at

www.hindawi.com
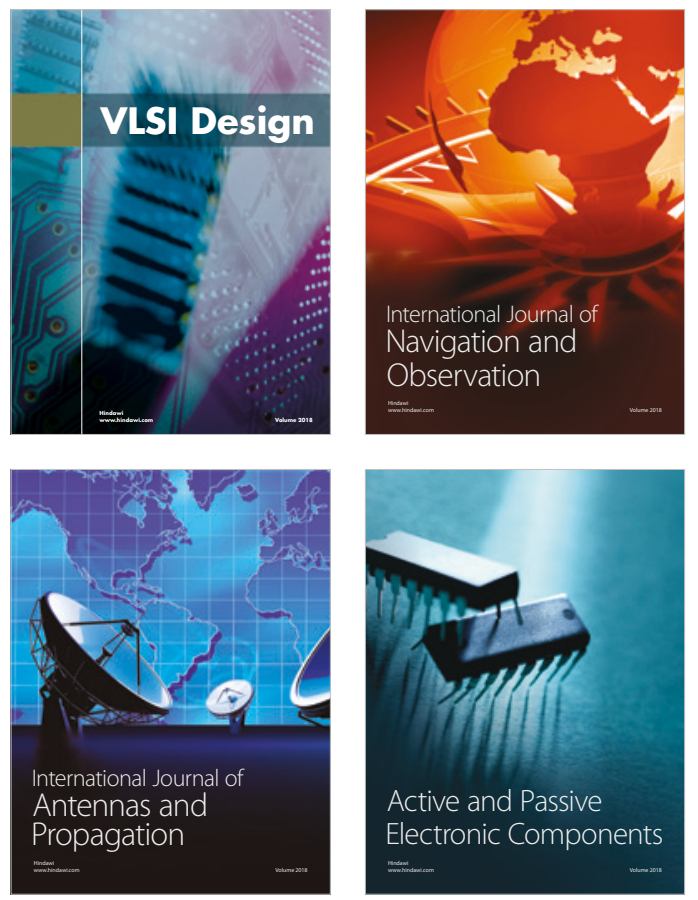
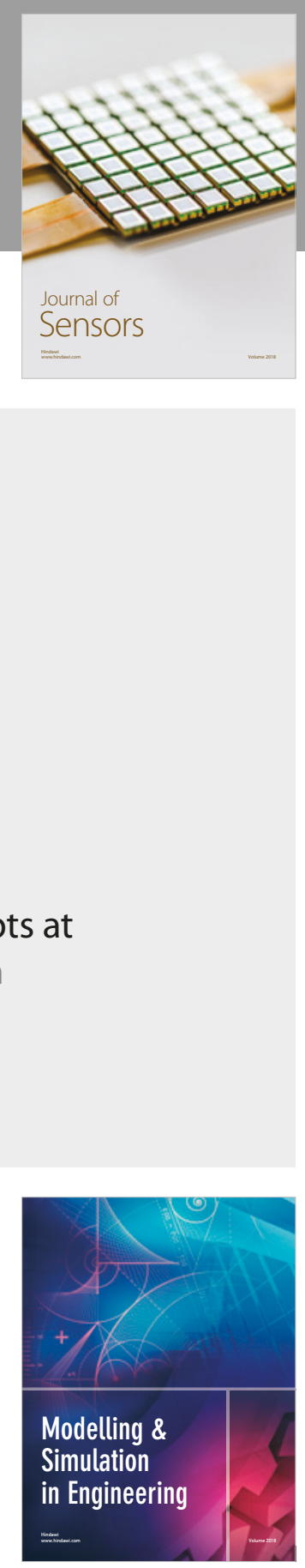

\section{Advances \\ Multimedia}
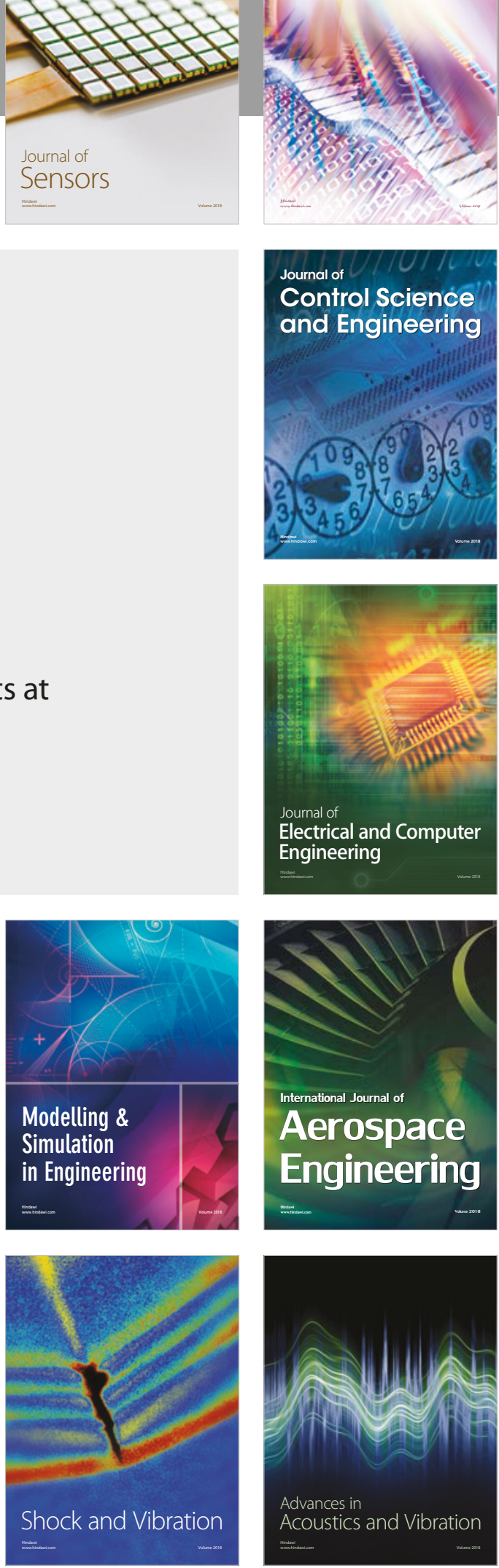